\title{
The Effectiveness of Play Therapy in the Management of Aggression and Stubborn Behavior of Mild Intellectual Disable Child (A Case Study)
}

\begin{abstract}
Muhammad Zakaria, Sabiha Dar, Ghinasha Chudary, Ejaz Hussain
${ }^{1}$ PhD Scholar, Department of Psychology University of Central Punjab Lahore Pakistan.

${ }^{2}$ Research assistant, Department of Psychology University of Central Punjab Lahore Pakistan.

${ }^{3}$ PhD Scholar, Department of Psychology University of Central Punjab Lahore Pakistan.

${ }^{4}$ Lecturer, National College of Business Administration \& Economic Lahore Pakistan.

Corresponding Author:

Abstract- Purpose of current article is to highlight the importance of play therapy in the management of aggression and stubborn behavior. The present study is based on a case of a boy who diagnosed with mild intellectual disability as well he had aggression and stubborn behavior. His undesirable behaviors were not decreased through prior treatment. The clinical psychologist at special education school were applied multiple psychological interventions of play therapy which included balloons of anger, bubble breaths relaxation exercise, the slow motion game and the mad game. Before the starting of therapy the aggression and stubborn behavior scales were filled by client's mother. On the bases of psychological test and detailed history the client was diagnosed with mild intellectual disability according to the criteria of DSM-5. The play therapy techniques were learned by client to use at home by himself. After fifteen therapeutic sessions the measure tools of aggression \& stubborn behaviors were again filled by client's mother. Results displayed the extreme reduction in the level of aggression and stubborn behavior. Furthermore he also improves his social functioning as stated by client's mother.
\end{abstract}

Keywords: Aggression, Intellectual Disability, Play therapy, Stubborn Behavior.
Muhammad Zakaria

Email: zakria108@gmail.com

Copyright (C) 2020: Muhammad Zakaria. This is an open access distribution, and reproduction in any medium, provided Access article distributed under the Creative Commons Attribution License the original work is properly cited License, which permits unrestricted use.

Citation: Muhammad Zakaria, Sabiha Dar, Ghinasha Chudary, Ejaz Hussain. "The Effectiveness of Play Therapy in the Management of Aggression and Stubborn Behavior of Mild Intellectual Disable Child (A Case Study), "Journal of Science, Computing and Engineering Research, 1(5), 126-130, November - December 2020.

\section{INTRODUCTION}

The aggression and stubborn behaviors is construed as covert responding of a person for instance, physical, emotional, and verbal. Since 1950s there are multiple behavioral interventions that have been used for multiple psychological and behavioral related issues, but now most of the psychologists and psychotherapists planned the play therapy intervention for children because of their little or no understanding of complex behavioral interventions as well as they easily learned through play and manage their problematic behavior and improve others skills. There are many well-known play therapy techniques which are used for the management of aggressive and stubborn behavior which include balloons of anger, bubble breaths relaxation exercise, the slow motion game and the mad game beat the clock [1].

There are many children, who suffer with multiple psychological and neurodevelopmental disorders as well as behavioral issues like aggression and stubborn behaviors. These problems are mostly common in those children who are with intellectual disability because of their low level of mental function as well as parental lack of concern toward the management and neglecting in multiple environments. The aggression and stubbornness both are learned behavior some individuals are taught from home environment and some from their friend, school teacher [2, $3]$. These clients are best treated by anger management training, behavior and play therapies approaches but commonly used the play therapy interventions for their easy understanding and learning $[4,5]$.

A Verity approaches are used to manage the aggression [6], and modify the stubborn behaviors the play therapy approaches is also one of these approaches [7]. A lot of empirical work $[8,9,10,11]$, showed that the play therapy approaches is significant effective for management and modification and anger and stubborn behaviors. The balloons of anger, bubble breaths relaxation exercise, the slow motion game and the mad game are best approaches of play therapy for anger management and stubborn behavior by client when used within the context self-management. Afterward the therapist goes through the play therapy 


\title{
The Effectiveness of Play Therapy in the Management of Aggression and Stubborn Behavior of Mild Intellectual Disable Child (A Case Study)
}

\author{
Available at https://jscer.org
}

approaches 2 or 3 times, to encourage the client for their own practice which means they manage themselves and cope from problematic behaviors.

Multiple researches work on the effectiveness of play therapy intervention in management of aggression and stubborn behaviors [5], found the severe difference of decrease the ADHD of children in experimental group compared to those in control group, while [7], revealed that the Overall play based techniques have been shown to contribute to a reduction in a constellation of symptoms related to aggression, stress, fears and anxiety, further studies measured the impact of play therapy treatment on treatment of youngsters with anger and stubborn issue. 96 researches were examined and results indicated that utilizing methods of play therapy treatment much of the time could positively affect treatment of these issues.

The above mentioned literature and applicability of play therapy approaches clearly mention that the play therapy approaches plus anger management and behavior therapy is effective treatment for the management of aggression and stubborn behavior. In our society there is a lack of education and awareness and psychological treatment, they think that aggression and stubborn behavior are also the symptoms of intellectual disability and it was developed with it like other symptoms of IDD that they didn't concern for its treatment. In the current paper investigators need to know the efficacy of play therapy approaches with a child who is intellectually disability while he has aggressive and stubborn behavioral problems that were associated with stress and social disturbance and he was diagnosed with intellectual disability disorders [12].

Client A.M is a 12 years old boy. He studies in grade two at special education institute Lahore. His birth order is first among two siblings, one sister. His father is 50 years old and educated up to metric \& works in Sony Company. His mother is 40 years old, she is educated till to Master \& she is house wife. He lives in a joint family system. His parent's socioeconomic status is middle class. He belongs to Lahore.

Client was referred to by his school teacher with presenting complaints of aggression, stubborn behaviors and intellectual \& adaptive deficits. The detailed clinical interview by his mother revealed that she faced some complications during her pregnancy. She had high stress due family conflicts during pregnancy. The client was born at the hospital. The client mode of delivery was the lower abdomen cesarean section; his first cry immediately. Client's mother further reported that the client achieved his milestones at appropriate ages except speech. He developed one word speech at the age of $3 \frac{1 / 2}{2}$ years and his parents took him to a speech therapist in Children's hospital for one year at the age of 4 years. His speech improved; after therapy he has fully developed speech according to his age. He was toilet trained at the age of $31 / 2$ years.

Client's mother reported at the age of 5 years, the client was admitted to a mainstream school. The client's results in kindergarten, nursery and prep class were excellent but in class one he did not perform well and his teacher reported about his poor performance. Client's mother further reported that at that time she didn't know about his abnormalities and most of the time she showed aggressive behavior and beat him on his poor performance. His mother explained that when he didn't perform in class one and failed then she took the client to psychologist for assessment and after assessment he was diagnosed with intellectual disability mild level. Due to these problems, the client's parents stopped him from going to school. After that he was admitted in a special education institute at the age of 9 years, in 2016 and he has been studying there since then. He is studying there in grade 2, and according to his teacher he had problems in intellectual and adaptive functioning as well as aggression and stubborn behavior. Client's mother also reported that at the age of 9 years client developed aggressive behavior toward his mother. He also shows demanding behaviors as his father fulfills all of his demands and pampers him a lot. The client shows tantrums by shouting and screaming whenever his demands are not met.

The following psychological scales were applied for the purpose of psychological assessment, to find out the problematic area, recovery and treatment planning.

- Case history form of university of central Punjab Lahore.

- Slosson intelligence test-4 (Richard L. Slosson; Revised by Bradley et al., 2017).

- Child progressive matrices (Morgan R. Walker, 1950).

- Vineland adaptive behavior scale-II (Sparrow, Domenic V. Cicchetti, and David A. Balla, 2005).

In conclusion the detailed history and psychological assessment indicated that the client has mild intellectual disability. The history further showed which is reported by his mother proves the statement of social learning theory. In this study the client also learned the aggression and stubborn behaviors from their parents which are revealed by his mother in detail in the interview.

\section{METHODOLOGY}

\section{A. Study Participant and Research design}

In this current study the single case study research method was used with a single research participant $(n=1)$. The further demographic information, case history and other related material are mention in introduction.

\section{B. Measures}

The Case history intake form of the University of Central Punjab clinical psychology department was used to collect the information, child history, family history, birth history, development, and school and attachment history. Intake form also focused to collect his history of sleep, insight, behaviors and its effects.

Children aggression scale-parent version (CAS-P), by (Jeffrey M Halperin et al., 2002) used to identify client 


\section{The Effectiveness of Play Therapy in the Management of Aggression and Stubborn Behavior of Mild Intellectual Disable Child (A Case Study)}

Available at https://jscer.org

aggression before and after the therapy. Scale has consisted 33 items and evaluates five subareas, verbal aggression, aggression against Objects and animals, provoked physical aggression, unprovoked physical aggression, and use of weapons. The reliability o of scale is $\alpha=.93$.

Self-made stubborn behavior baseline scoring chart was filled by the client's mother and teacher to score the level of the client stubborn behaviors at school and home environment. The scale was used due to lack of availability of valid scale for child stubborn behavior. Self-made stubborn behavior scale included the activating events, behavior, consequences, frequency, duration and scoring of the behaviors. The scale was initially discussed with other therapists then applies for the study purpose.

\section{Procedure \& Therapeutic Intervention}

First of all therapists gain the permission from the school and assessment tools authorities and ethical consideration of the current study was discussed. After that the informed consent was filled by participant, mother and assured the confidentiality of identifying information. The nature and purpose of present study was briefly discussed with client, teacher and mother. All the therapeutic intervention of play therapy was selected for client based on its applications and discussed with other authors of current study. Therapy sessions were planned based on client and his mother availability at school. It was planned that two sessions would be suitable in a week. Initially researcher conducted a detail Interview, administered the psychological assessment tools with detailed then administrated child aggression scale and self-made stubborn behavior baseline. In the very first sessions therapist engaged the client in different activities i.e. stars charts, first impression charts, color pictures charts, token economy chart for the purpose to build rapport in order to make client comfortable and engage assessment and therapy. Client's mother was psycho-educate about the nature of client. Initially the continuous nontangible reinforcement was planned for client. The client's mother and teacher rated them between $0-100 \%$ intensity levels of his aggression and stubborn behavior.

After 3-4 sessions' play therapy technique started working and client learned the first technique to manage his anger and stubborn behaviors. For the management of his problems the further technique was applied. Play therapy techniques were consisted of balloons of anger, bubble breaths relaxation exercise, the slow motion game and the mad game. After the management times the balloons of anger, bubble breaths relaxation exercises were also learned by the client to use at home by himself. The entire therapeutic intervention treatment was contained fifteen sessions. After the completion of fifteen session's child aggression scale and self-made stubborn behavior baseline rating test were again filled by his mother to assess the intensity of aggression and stubborn behaviors. The above listed problems subjective ratings were done. His mother and teacher stated that he managed his self very well and also make many friends at school; therefore the total treatment period was of two and half months.

\section{RESULTS}

Therapeutic outcome of play therapy interventions presented that play therapy intervention are very effective in the management of aggression and suborn behaviors. See the (Table I-II, III).

Table I. Show the pre-test and post-test raw score and Std, score of children aggression scale.

\begin{tabular}{cccc}
\hline & $\begin{array}{c}\text { Pre-test } \\
\text { score }\end{array}$ & $\begin{array}{c}\text { Post test } \\
\text { score }\end{array}$ & $\begin{array}{c}\text { Pre-post-tests } \\
\text { differences }\end{array}$ \\
\hline $\mathrm{N}=1$ & & & \\
Raw score & 109 & 45 & 64 \\
Std. score & 11 & 68 & 05 \\
\hline
\end{tabular}

Table II. Display the pre- test and post-test raw score and Std, score of self-made rating scale of child stubborn behavior

\begin{tabular}{cccc}
\hline & $\begin{array}{c}\text { Pre-test } \\
\text { score }\end{array}$ & $\begin{array}{c}\text { Post test } \\
\text { score }\end{array}$ & $\begin{array}{c}\text { Pre-post-tests } \\
\text { differences }\end{array}$ \\
\hline $\mathrm{N}=1$ & & & \\
Raw score & 85 & 30 & 55 \\
Std. score & 9 & 80 & 06 \\
\hline
\end{tabular}

Table III. Client's subjective rating of pre and post-test by client's mother of his aggression and stubborn behaviors

\begin{tabular}{cccc}
\hline $\begin{array}{c}\text { Problematic } \\
\text { Areas }\end{array}$ & $\begin{array}{c}\text { Pre-test } \\
\text { score } \%\end{array}$ & $\begin{array}{c}\text { Post test } \\
\text { score } \%\end{array}$ & $\begin{array}{c}\text { Pre-post-tests } \\
\text { differences } \%\end{array}$ \\
\hline $\begin{array}{c}\text { Verbal } \\
\text { aggression }\end{array}$ & $95 \%$ & $30 \%$ & $65 \%$ \\
$\begin{array}{c}\text { Aggression } \\
\text { against Objects } \\
\text { and animals } \\
\begin{array}{c}\text { Provoked } \\
\text { physical }\end{array}\end{array}$ & $80 \%$ & $25 \%$ & $55 \%$ \\
$\begin{array}{c}\text { aggression, } \\
\text { Unprovoked } \\
\text { physical } \\
\text { aggression } \\
\text { Use of } \\
\text { weapons }\end{array}$ & $70 \%$ & $30 \%$ & $60 \%$ \\
Resistance & $85 \%$ & $30 \%$ & $40 \%$ \\
\hline
\end{tabular}

Note: The pre and post results show the difference after treatment of play therapy interventions. 


\title{
The Effectiveness of Play Therapy in the Management of Aggression and Stubborn Behavior of Mild Intellectual Disable Child (A Case Study)
}

\author{
Available at https://jscer.org
}

\section{DISCUSSION}

Play therapy is used with a mild intellectual disable client for management of his aggression and stubborn behaviors in clinical practice. Current paper revealed its efficacy in (table I, II \& III), it is directed that there was a huge difference in the management of aggression and stubborn behavior after applying the play therapy interventions. It included balloons of anger, bubble breaths relaxation exercise, the slow motion game and the mad game. Client's mother reported the improvement of client during therapy sessions like "now he is waiting for fulfilling his demand until he completes his 5 minutes homework, he also decreases his aggression toward his mother. Client's mother also stated that now he focuses on study \& completed his homework daily based on time. The client's mother explains the pre-post variance in result of aggression \& stubborn behaviors which showed the relationship among behavioral issues and therapeutic treatment, for example aggression, stubborn behavior and play therapy and behavior therapy. There was a clear difference shown in aggression (Table I). It was also stated that (see table II) clients feel decreasing in his stubborn behaviors [7]. After developing the management about him indicated the connection between tolerance and how to relax his state of mind and body as well as environment. Here play therapy practices were very supportive in handling his aggression and stubbornness. Further activities were also applied as play therapy interventions on clients like he started engaging himself in studies, homework preparing, attending training classes thus he became extra busy in helpful exercises and felt less aggression \& stubbornness. The result clearly showed the effectiveness due to play therapy intervention and pushed him to positive and comforting activities [10], showed that the play therapy approach is significantly effective for management and modification in anger and stubborn behaviors. Play therapy is also useful in emerging his awareness about the role of parents, teacher, peers, home and school environment, as he said "now I feel less anger and stubbornness and also listen to mother, now associations with mother is better, my father gave me time, I also communicated with him, I did not feel aggression." This change is also attributed to play therapy because whenever he talked with his mother he became aggressive, however after learning play theory interventions, it was easier to engage with classmates and friends in different activities as he reported. Client's scores, subjective expression and observation showed that play therapy is very useful and effective in the management of aggression and stubborn behaviors. Our conclusions are also supported by the findings of $[7,8,9$, and 10].

\section{CONCLUSION AND FUTURE DIRECTIONS}

It is decided that play therapy intervention substitute's provocation, the client gains therapeutic consequence that involves a sense of management of over problematic emotional and behavioral stimulation, which helps him in reinstating societal, educational and professional functioning. Play therapy originated to be the important aspect in the handling of aggression and stubborn behavioral problems. Current paper reveals the efficacy of psychological intervention in Pakistani (Asian) culture where people express their aggression in physical actions. The current conclusion is strongly suggested to specialists that deal with their client aggression and stubbornness through play therapy interventions and must reflect the significance of play therapy in their management plan to socialize clients. The present study findings suggested that the researcher must concentrate on the examination of efficacy of play therapy interventions and behavior therapy with larger samples.

\section{Ethical Compliance Section}

Funding disclosure: The author(s) didn't receive any financial support for the research, authorship, and/or publication of this article.

Conflict of interest: The author(s) declared no potential conflicts of interest with respect to the research, authorship, and/or publication of this article.

Informed Consent: The researcher first filled the written consent form from the parents of children. The participant's mothers and teachers were asked to fill questionnaires based on the given instructions.

\section{REFERENCES}

[1] Hall, Tara., \& Kaduson, Heidi., \& Schaefer, Charles. (2002). Fifteen Effective Play Therapy Techniques. Professional Psychology Research and Practice. 33. 515-522. 10.1037//07357028.33.6.515.

[2] Bandura, A., Barbaranelli, C., Caprara, G. V., \& Pastorelli, C. (1996). Mechanisms of moral dis-engagement in the exercise of moral agency. Journal of Personality and Social Psychology, 71(2), 364-374. https://doi.org/10.1037/0022-3514.71.2.364

[3] Shanahan, M, (1993). Poverty, Parenting, and Children's Mental Health. American Sociological Review, 58(3), 351-366. Retrieved October 3, 2020, from http://www.jstor.org/stable/2095905

[4] Havighurst, Sophie \& Wilson, Katherine \& Harley, Ann \& Prior, Margot \& Kehoe, Christiane. (2010). Tuning in to Kids: Improving emotion socialization practices in parents of preschool children-findings from a community trial. Journal of child psychology and psychiatry, and allied disciplines. 51. 1342-50. 10.1111/j.1469-7610.2010.02303.x.

[5] Jafari, Niloufar \& Mohammadi, Mohammad-Reza \& Khanbani, Mehdi \& Farid, Saeedeh \& Chiti, Parisa. (2011). Effect of Play Therapy on Behavioral Problems of Maladjusted Preschool Children. Iranian journal of psychiatry. 6. 37-42.

[6] Snyder, K. V., Kymissis, P., \& Kessler, K. (1999). Anger management for adolescents: Efficacy of brief group therapy. Journal of the American Academy of Child \& Adolescent Psychiatry, 38(11), 1409-1416. https://doi.org/10.1097/00004583199911000-00016

[7] Davis, T.N., \& Bailey, J. (2019). Play-Based Interventions for Aggressive Children: Tools for Clinicians

[8] Webster-Stratton, Carolyn \& Reid, M. \& Hammond, Mary. (2001). Preventing Conduct Problems, Promoting Social Competence: A Parent and Teacher Training Partnership in Head Start. Journal of clinical child psychology. 30. 283-302. 10.1207/S15374424JCCP3003_2. 
The Effectiveness of Play Therapy in the Management of Aggression and Stubborn Behavior of Mild Intellectual Disable Child (A Case Study)

Available at https://jscer.org

[9] Sukhodolsky, D. G., Smith, S. D., McCauley, S. A., Ibrahim, K., \& Piasecka, J. B. (2016). Ryan, V., \& Bratton, S. (2008). Child-centered play therapy for very young children. In C. E. Schaefer, S. Kelly-Zion, J. McCormick, \& A. Ohnogi (Eds.), Play therapy for very young children (p. 25-66). Jason Aronson.

[10] Ray, D., Bratton, S., Rhine, T., \& Jones, L. (2001). The effectiveness of play therapy: Responding to the critics. International Journal of Play Therapy, 10(1), 85108. https://doi.org/10.1037/h0089444

[11] Christine, M. Daly., MC, USA. Thomas., Grieger, MC. USN., Mary.(2002). A 4-Year-O1d with Oppositional Defiant Disorder, Military Medicine, Volume 167, Issue 5, May 2002, Pages 442-444, https://doi.org/10.1093/milmed/167.5.442

[12] Diagnostic and Statistical Manual of Mental Disorders,(2013). American Psychiatric Association, 5th ed.; American Psychiatric Association: Washington, DC, USA,

[13] Richard L. Slosson; Revised by Bradley T. Erford, PhD, Sue L. Larson, PhD, and Steven W. Slosson (2017). Slosson Intelligence Test-4th Edition; United States of America

[14] Kelley, J. E., Walker, M. R., \& Sayer, J. S. (1989). The origins of CPM: a personal history. PM Network, 3(2), 7-22.

[15] Sparrow, S.S. A Balla, D.A. A Cicchetti, D.V. (2005). Vineland Adaptive Behavior Scales, Second Edition: Survey Forms Manual; books.google.com.pk/books?id=b_ddMQAACAAJ 